\title{
La seda fina del viure
}

\author{
Dolors Udina
}

Universitat Autònoma de Barcelona. Facultat de Traducció i d’Interpretació

Edifici $\mathrm{K}$

08193 Bellaterra (Barcelona)

dolors.udina@uab.cat

ORCID: 0000-0002-5407-6954

\section{Resum}

En aquest article es planteja la necessitat i vigència de les retraduccions, tant en català com en altres llengües, i se n'analitzen alguns casos. Concretament, es parla de la retraducció al català de Mrs Dalloway a la primeria del segle XXI i els canvis propiciats per les convencions literàries de cada època respecte a la traducció dels anys trenta del segle xx. També s'exposa la retraducció feta per la mateixa persona d'un llibre de Jeanette Winterson trenta anys després.

Paraules clau: retraducció; Virginia Woolf; Jeanette Winterson

Abstract. The delicate silk of living

This article is a reflection on the need and validity of new translations of the same work, in Catalan as well as other languages, and some cases are analyzed. As a specific case, there is the new translation of Mrs Dalloway at the beginning of the 21st century and the changing literary conventions in each period of time. There are also some comments about the new translation of The Passion by Jeanette Winterson made by the same translator thirty years later.

Keywords: retranslation; Virginia Woolf; Jeanette Winterson

Les traduccions envelleixen perquè són una reescriptura de l'obra original que fa el traductor a partir d'una interpretació personal determinada pel llenguatge de la traducció i la cultura d'arribada. A l'hora de traduir, la intenció que tenim és dir el mateix que diu l'original i, per tant, podríem pensar que, si una traducció és bona, pot durar els anys que calgui. Històricament s'ha partit de la base que un dels principis de la traducció és escriure com escriuria l'autor si escrivís ara en català, però això no deixa de ser una premissa utòpica, perquè probablement l'autor ara no escriuria l'original tal com el va escriure, perquè són uns altres temps, perquè partiria d'un context diferent i perquè l'experiència dels anys l'hauria canviat. És inevitable que la traducció reflecteixi la llengua i l'estil de l'època en què es fa, i possiblement és això el que fa que sigui transitòria. 
Una traducció (com l'original) és deutora del temps en què es va emprendre i envelleix perquè és una reescriptura de l'obra original en la qual el context, tant l'intratextual (les paraules no tenen mai el mateix significat ni les mateixes connotacions en les diferents llengües) com l'intertextual (les referències a altres textos i gèneres de la literatura original), canvia per adaptar-se al lloc i l'època en què es tradueix. Una traducció és una lectura original d'un text i és testimoni de la relació que mantenen un autor i aquest lector particular que és el traductor, que, a part del seu imaginari concret, sempre està lligat al seu temps i a la manera com es veuen i es diuen les coses en aquest temps, la manera que es considera més apta, millor, més correcta. Aquesta relació amb el temps permet posar al dia, i comprendre, el tipus de lectura que es fa d'una obra en un moment donat, el paper que té la traducció en determinades èpoques de la Història, la necessitat de retraduir, la incomprensió de l'original causada per la distància temporal, el lloc de la retòrica i de l'estètica en aquell moment, etc.

D'un llibre original (d'un clàssic), no en fem mai la mateixa lectura: si el llegim en una època, o a una edat determinada, hi veiem una sèrie de coses; en una altra, en veiem altres de totalment diferents. Si equiparem la traducció amb la lectura, doncs, veiem que, quan tornem a llegir un clàssic, ens diu coses diferents que un temps abans. Una traducció, cada cop que es torna a dur a terme, posa l'èmfasi en un aspecte nou, destaca elements diferents de l'original i, d'aquesta manera, pot restituir alguna cosa que s'ha perdut pel camí. Em sembla que la base de la literatura és la interpretació personal del lector: no hi ha mai una sola lectura; per tant, no es pot estar mai segur d'haver fet la versió definitiva de res. Cada traducció és una trobada única d'un text amb les preocupacions i la personalitat del traductor.

Quan es torna a traduir una obra ja traduïda, l'objectiu no és superar la traducció anterior com si es tractés de trobar la veritat definitiva de l'original. No, cada època hi trobarà una veritat, a l'original. El que fa la retraducció és evidenciar la distància — lingüística, històrica, cultural— entre l'original i el moment de la nova traducció. És a dir, que la nova traducció fa de mirall històric. I, en tant que mirall, sempre és una representació inacabada i inexacta que deixa oberta, per força, la porta a noves traduccions.

Qualsevol traducció s'afegeix al llegat d'una cultura. Hi ha llibres que van entrar a formar part de la tradició en català i que van ser cabdals en la formació de diverses generacions de lectors i, per diversos factors, necessiten una nova aproximació perquè s'hi pugui reflectir una nova generació. Penso, per exemple, en la traducció d'A Catcher in the Rye (1951) de Salinger. Hi havia una traducció dels anys seixanta de Xavier Benguerel, amb el títol de L'ingenu seductor, i va ser retraduïda per Josep Maria Fonalleras i Ernest Riera als anys noranta amb el títol d'El vigilant en el camp de sègol. El llibre és el mateix, però la idiosincràsia del protagonista de 17 anys en la primera traducció, que s'ajustava als lectors catalans del moment, vist des d'ara, traïa la irreverència o l'atreviment d'un antiheroi, Holden Caulfield, que era una part tan essencial del llibre original. (Cal dir, també, que sembla que la traducció de Benguerel va ser feta a partir del francès, cosa que podia contribuir a desvirtuar l'original.) De totes maneres, i amb tots els 
defectes, L'ingenu seductor va ser un llibre que va marcar molts lectors dels anys setanta. Potser la traducció que vam llegir era el que podíem llegir, el que esperàvem, els lectors d'aquella època. És curiós i val la pena destacar que $A$ Catcher in the Rye té una història similar en molts idiomes i, en pràcticament tots, se n'han fet traduccions i retraduccions que esmenen la plana a les anteriors. Potser per la «gosadia» $\mathrm{i}$ frescor de l'original, aquest és un cas paradigmàtic que reforça la idea que mentre un original no caduca mai, una traducció, és a dir, la interpretació d'aquest original en cada moment determinat, sí.

En alguns casos, la crítica a la traducció ha propiciat que es fes una traducció nova. En un interessant llibre titulat This Little Art, Kate Briggs explica la història de les traduccions a l'anglès dels Buddenbrooks i La muntanya màgica de Helen Lowe-Porter, als anys vint, que havien rebut sempre moltes lloances fins que el 1995 el crític Timothy Buck en va fer una crítica furibunda assegurant que les traduccions eren plenes d'errors de comprensió i menystenint l'actitud de la traductora, que deia que «no enviava mai una traducció a l'editor fins que tenia la sensació d'haver escrit el llibre ella mateixa» (Briggs 2017: 75) i que, en les seves traduccions, oferia la seva pròpia experiència d'autora creativa. Contra aquesta aproximació, el crític defensava que una traducció, per ser modèlica, «havia de ser fidel a l'original i llegir-se amb flü̈desa» (Briggs 2017: 84), i això va generar una resposta al Times Literary Supplement de Lawrence Venuti en què l'acusava de fer gala de «la típica condescendència acadèmica» (Briggs 2017: 84) envers la traducció i els traductors i defensava els possibles errors de la traductora sobre la base que els criteris del que és una bona traducció canvien amb el temps. Hi ha una estètica tàcita de la traducció (diu Venuti) que, com totes les tradicions estètiques, és necessàriament del seu temps. La conclusió de l'autora del llibre esmentat, Kate Briggs, és: «Si no vols fer errors, no facis traduccions» (Briggs 2017: 86). I cita Virginia Woolf i es pregunta: «Escrivim millor, llegim millor que fa 400 anys?» (Briggs 2017: 88).

Hi ha casos en què una nova traducció és crucial perquè l'anterior, dels anys trenta, s'ajustava amb excés a l'opinió dels traductors del significat de l'obra. J. M. Coetzee analitza el cas de la primera traducció de Kafka a l'anglès, feta per un matrimoni d'escocesos, els Muir, que partien de la base que tota l'obra de Kafka tenia un significat religiós i consideraven que la seva tasca era guiar els lectors anglesos a través d'aquests textos nous i difícils i presentar Kafka com «un geni religiós... en una època d'escepticisme» (Coetzee 2004: 98). Als anys noranta va sortir una nova traducció d'El castell i s'ha tornat a traduir a l'anglès tota l'obra de Kafka sense el biaix religiós.

Shakespeare és un cas paradigmàtic de la necessitat de retraduccions, però penso que, en aquest cas, és més per la necessitat de molts poetes d'incorporar els sonets al seu cànon particular i mirar de dir-los en la llengua pròpia, que no perquè les versions anteriors hagin quedat obsoletes o siguin difícils d'entendre. Tenim en aquests moments més de cinc versions publicades dels sonets de Shakespeare (i alguna més a la xarxa). La conclusió és que som afortunats de poder llegir tantes versions «modernes» de Shakespeare, perquè davant la impossibilitat de traslladar tots els sentits que Shakespeare era capaç d'encabir en un vers, 
les diferents aproximacions formen un mosaic que ajuden a aprofundir en els sonets.

Si parlem de teatre, a part de les traduccions de Manuel de Montoliu del principi del segle Xx, durant molts anys les traduccions que es portaven al teatre eren les de Josep Maria de Sagarra, que traduïa Shakespeare per a aquell públic que abans de la guerra omplia els teatres on es representaven les seves obres en vers. Els «shakespeares» de Sagarra no eren per a la televisió o per al cinema, sinó per ser declamats davant un públic que admirava la seva retòrica. Després de les de Sagarra van venir les traduccions de Salvador Oliva (com a encàrrec de TV3 per fer-les per televisió), les de Desclot, normalment en vers per a l'escena, i les de Joan Sellent, que són les que darrerament es porten a escena i que es distingeixen per la qualitat i naturalitat de la llengua, que fan de Shakespeare el nostre contemporani.

És molt interessant el cas de l'Odissea de Carles Riba, que la va traduir l'any 1919 i la va tornar a traduir el 1948. En el pròleg a la segona versió, Riba explicava que a la primera traducció intentava encabir-hi tot el que descobria en l'original, amb molta atenció a l'etimologia, i que es trobava «encastat a la superfície del text, sense ben bé moure'm amb ell» (Riba 1953: 12). Llavors, trenta anys després, reconeix que el que calia, més que dominar el text, era «deixar-se dur per la força que d'ell es comunica [...] córrer a voga i a vela llengua pròpia enllà» (Riba 1953: 12). En la segona traducció, pensa que el que cal és fer de l'Odissea «un monument de la llengua pròpia». El temps, les circumstàncies de l'època i la seva pròpia experiència de poeta van donar a la traducció un enfocament diferent. En aquest cas, doncs, és el traductor mateix que veu la necessitat d'una nova traducció, de rellegir l'original d'una altra manera.

És interessant, i no gens estrany, que després de Riba no s'hagi atrevit ningú a traduir l'Odissea en vers (per bé que sí que ho ha fet Joan Francesc Mira en prosa). M'infon respecte parlar de traduccions dels clàssics (grecs, llatins, hindús, etc.) perquè escapen al meu àmbit de coneixements, però malgrat tot ho trobo un tema apassionant. El 2017 va sortir una nova traducció a l'anglès de l'Odissea, de les primeres fetes per una dona, que va causar sensació en el món acadèmic i lector nord-americà. Emily Wilson va raonar moltes de les seves decisions de traducció en una interessantíssima sèrie de tweets que van posar a l'abast de tothom els complicats raonaments que fa el traductor d'una llengua com el grec homèric per escriure el text en un anglès contemporani. Només amb la primera frase del llibre ja sembla marcar una nova manera d'abordar la història, segons que diu ella, per convidar els lectors a respondre més activament al text. Allà on Riba diu «Conta' $m$, Musa, aquell home de gran ardit...», i les anteriors traduccions a l'anglès deien «Sing to me of the man, Muse...» (Fagles) o «Sing in me, Muse, and through me tell the story / of that man skilled in all ways of contending» (Fitzgerald), Wilson diu «Tell me about a complicated man». El seu raonament és que «la idea que Homer ha de sonar heroic i antic» implica un sistema de valors que inclou «acceptar aquesta idea tan jeràrquica de la societat com si l'heroisme fos precisament això» (North 2017). Explicar la història en una llengua més planera permet que els lectors vegin Ulisses i la seva societat d'una manera diferent. 
Quan es retradueix una obra clàssica, l'obra estableix una conversa amb ella mateixa en les diverses traduccions, versions i adaptacions, i els lectors aporten aquesta consciència i experiència a la seva lectura. Una traducció és l'arribada d'una cosa nova al món, una cosa nova per afegir a la conversa. La traducció és un procés fonamentalment collaboratiu. Tens deutes amb tots els traductors anteriors. Subscric una frase que vaig llegir a Joan Sellent parlant de la seva retraducció de L'illa del tresor: «Reivindico la pràctica de beure dosificadament dels encerts dels precursors» (Sotorra 2002). Encara que rebutgis l'obra d'un traductor anterior, hi estàs en deute perquè tens alguna cosa a rebutjar.

El 2018 em van encarregar una nova traducció d'una novella que havia traduitt trenta anys abans. L'obra és The Passion, de Jeanette Winterson, una de les primeres novelles que vaig traduir, el 1988, només un any després que es publiqués l'original. Quan vaig rebre l'encàrrec, vaig pensar que seria fàcil revisar la traducció anterior, esmenar alguns errors que hi pogués haver i, com si diguéssim, rejovenir-la. Em va semblar molt estimulant tornar a enfrontar-me a un text que té molta substància (i molta vida) per veure com el llegia tants anys després. Tenint en compte que el moment i les circumstàncies en què fem una traducció tenen una incidència definitiva en el resultat, m'intrigava descobrir com seria la meva intervenció en un mateix text. És evident que la traducció antiga deia el mateix, o «gairebé el mateix», que l'original; podria dir-se que a grans trets era una traducció correcta, però, refent-la, vaig poder sospesar molt més cada paraula i cada sensació per reconèixer el pes que tenia dins del text i copsar més bé el sentit general de l'obra. Quant a la llengua, vaig constatar com ha canviat el català literari dels vuitanta fins ara i, evidentment, que trenta anys de treballar amb la llengua ajuden a treballar-la més bé.

No cal dir que hi ha una diferència entre traduir una obra just quan surt en l'idioma original o fer-ho anys després. Jeanette Winterson va escriure La passió, una de les primeres novelles que va publicar, l'any 1987, tot just un any abans que Columna la publiqués a Catalunya. Era una autora totalment desconeguda i, tot i que la novel.la no va passar desapercebuda del tot, no va tenir prou èxit perquè l'editorial volgués publicar més obres seves. Des de llavors, Winterson ha escrit unes vint obres més, entre ficció i assaig, moltes de les quals s'han publicat en castellà. Quan l'editorial Periscopi es va interessar per l'obra de Winterson, va decidir començar un altre cop per La passió, actualment ja introbable en la versió anterior, per continuar per l'última obra escrita per l'autora, trenta anys després, Frankisstein.

Quan tradueixes algú per primer cop, un contemporani, has de fer pràcticament un facsímil de l'obra per fer sentir la veu de l'autor. En canvi, quan ja has llegit unes quantes obres de l'autora i tens més consciència del lloc que ocupa dins de la literatura de la llengua original, la traducció està molt més intervinguda per l'experiència lectora d'anys. Crec que la diferència principal entre la primera versió i la darrera és la importància que he après a donar al procés de revisió i a la necessitat de repensar una vegada i una altra cadascuna de les frases per aconseguir que una traducció pugui ser considerada una obra literària i entrar a formar part de la tradició pròpia. Tanmateix, llegint el que diu Jeanette Winterson a Why 
Be Happy When You Could Be Normal, potser és més important aprendre a llegir els silencis que no pas les paraules: «Quan expliquem una història, hi exercim un control, però de tal manera que deixem un espai, un buit. És una versió, però no la definitiva. I potser esperem que algú altre pugui sentir-ne els silencis i la història pugui continuar, que pugui ser explicada una vegada i una altra» (Winterson 2011: 8).

Un dels encàrrecs més apassionants que he rebut mai va ser el de traduir al català Mrs Dalloway, una obra fascinant que em va fer veure la importància de ser prou transparent en una traducció per mantenir el lector en estat d'alerta i de tensió. Quan dic transparent no vull dir que em volgués fer invisible per fer veure que no hi havia la intervenció d'una traductora, sinó que volia aconseguir un text despullat de tot afany de guiar el lector, lliure d'enfarfecs lingüístics. La primera traducció de Mrs Dalloway datava de 1930 i era de Cèsar August Jordana, un traductor d'una trajectòria inigualable. Si comptem que va fer la traducció només quatre anys després que es publiqués a Anglaterra i que Virginia Woolf encara no era la figura literària en què es va convertir al llarg del segle xx, podríem qualificar la traducció d'admirable. Llavors encara no s'havia sentit parlar de l'stream of consciousness (flux de consciència o monòleg interior) inaugurat, podríem dir, per Joyce i Woolf mateixa, i no devia ser tan fàcil, a l'hora de traduir, arribar a reconèixer que no és el narrador que conta la història, sinó que són els personatges mateixos que l'integren els qui s'expliquen.

Si es compara la meva traducció amb la de Jordana, de seguida es veuen diferències que poden adjudicar-se a la manera de traduir i a les convencions lingüístiques de cada moment. Començant pel títol: ell no tradueix el títol de Mrs, cosa habitual en aquells temps; jo li dic «Senyora Dalloway». Ell tradueix el nom dels personatges, Lucy /Llúcia, Big Ben / Gros Ben; i no posa articles als noms, Peter Walsh / Pere Walsh, Hugh / Huc, Evelyne / Evelina. Jordana sol posar «can» davant del nom d'una botiga, d'una casa determinada: can Rumpelmayer; el camió de can Durtnall. Hi ha maneres de dir dels anys trenta que han quedat obsoletes. D'una noia que s'estava dreta a la vorera diu: Allí es tenia (S'estava allà, en la meva traducció.) I els llurs, hom i quelcom que la majoria de traductors no fem servir actualment.

Per demostrar la subjectivitat i la importància de les sensacions en una traducció, vull parlar d'una de les frases que més em va fer reflexionar quan traduïa Mrs Dalloway. A part de la primera frase, d'una claredat diàfana que es torna a trobar comptades vegades al llarg del llibre (Mrs Dalloway said she would buy the flowers herself) i on pràcticament no hi ha diferències entre versions, ens trobem gairebé tot seguit amb les expressions: «What a lark! What a plunge!». S'han escrit pàgines i pàgines sobre aquestes dues exclamacions, sobretot la segona, que molts estudiosos interpreten com un parallelisme amb el plunge de Septimus Warren Smith quan se suïcida tirant-se per la finestra. És increïble la diversitat de les traduccions d'aquestes dues frases: de les italianes «Che emozione! Che tuffo al cuore!», «Que gioia! Che terrore!», «Che alegria! Che tuffo!»; a la francesa «Que de rires! Et de plongeons!», a les castellanes «iQué emoción! ¡Qué zambullida!», «Qué deleite! Qué zambullida!»o «iQué fiesta!, ¡Qué aven- 
tura!», i a la catalana d'en Jordana: «Quina delícia! Quin cabussó!». La meva primera traducció va ser «Quin deliri! Quina capbussada!» (Segons el diccionari, lark, a banda d' 'alosa', que aquí no funciona, vol dir 'fer alguna cosa per divertir-se, especialment una atzagaiada o gosadia'.) El que em costava era imaginar la Clarissa Dalloway obrint la finestra un dia especialment lluminós i dient això de quina capbussada. Finalment, després de molt parlar-ne i pensar-hi, vaig trobar una opció que em va semblar bona: «Quin esclat de vida! Quina plenitud!». És veritat que amb «plenitud» perdia el sentit de «llançar-se» que implica el plunge, sobretot tenint en compte que cinc frases més avall surt el verb plunge, que havia de traduir de la mateixa manera. Ho vaig resoldre traduint aquest segon com «es capbussava de ple». Traduir és decidir i moltes vegades fins que no et decideixes no pots seguir endavant. En aquest cas, vaig sentir la seguretat que buscava. I així va quedar.

Jordana no disposava, tampoc, de l'ajut dels centenars d'estudis que hi ha sobre l'obra de Virginia Woolf, que em podien ajudar en algun moment de desconcert davant el significat d'alguna frase determinada. Mentre feia la traducció, tenia al meu voltant algunes traduccions al francès, l'italià i el castellà. Això, que en principi semblaria que facilita la traducció, en realitat fa aprofundir tant en cada frase i calibrar amb tanta exactitud el que diu l'original que el temps passa sense que te n'adonis. És una manera de reunir en la traducció les opcions preses pels traductors en èpoques diferents i confio que resulti en la millora de la traducció.

Traduir aquesta obra té unes complicacions especials. A partir d'una primera frase que s'entén perfectament, quan la Clarissa Dalloway diu que comprarà ella mateixa les flors, ja no hi ha res que sigui evident. És com si miréssim un quadre amb la imatge de la protagonista de qui els diversos personatges que graviten al seu voltant i la ciutat on habita van desentranyant el misteri amb paraules. No sempre saps exactament què passa (tot i que en definitiva no passa res), però com més llegeixes, més illuminat queda el personatge principal i més enlluernat queda el lector. Com més treballava en la traducció, llegint i rellegint les frases carregades de poesia que va desgranant Virginia Woolf, més contingut hi trobava i més em veia obligada a traslladar. És en aquest aspecte que buscava la transparència que permetés al lector poder arribar tan a fons com has d'arribar quan tradueixes. Parafrasejant Nicole Brossard, el que es llegeix en una obra literària és «la seva energia, i és sens dubte el que serà més difícil de traduir, perquè l'energia és el que es desprèn del calibratge, el dispendi o la contenció en un text i és aquesta incandescència, aquesta seda fina del viure, el que caldrà traduir».

\section{Referències bibliogràfiques}

Briggs, Kate (2017). This Little Art. Fitzcarraldo Editions.

Brossard, Nicole (2017). I de sobte sóc aquí a punt de refer el món. Trad. Antoni Clapés. Barcelona: Cafè Central.

Coetzee, J. M. (2004). Costas extrañas. Ensayos 1986-1999. Trad. Pedro Tena. Barcelona: Random House Mondadori. 
NorTh, Anna (2017). (en línia) <https://www.vox.com/identities/2017/11/20/16651634/ odyssey-emily-wilson-translation-first-woman-english>.

Sotorra, Andreu (2002). «Editors amants de bucaners». Avui Cultura (28 febrer), p. 17.

Winterson, Jeanette (2012). Why Be Happy When You Could Be Normal. Londres: Vintage.

Woolf, Virginia (1930). Mrs Dalloway. Trad. Cèsar August Jordana. Badalona: Proa.

- (2013). La senyora Dalloway. Trad. Dolors Udina. Barcelona: La Magrana. 